\title{
Associations between intake of added sugars and intakes of nutrients and food groups in the diets of German children and adolescents
}

\author{
Ute Alexy ${ }^{\star}$, Wolfgang Sichert-Hellert and Mathilde Kersting \\ Research Institute of Child Nutrition (FKE), Dortmund, Germany
}

(Received 8 July 2002 - Revised 3 February 2003 - Accepted 3 April 2003)

\begin{abstract}
The aim of the present analysis was to evaluate the effect of intake of added sugars on intakes of nutrients and food groups. We used a mixed linear model (PROC MIXED) to analyse data from the Dortmund Nutritional and Anthropometric Longitudinally Designed (DONALD) study (an ongoing longitudinal cohort study between infancy and adulthood). Between July 1985 and August 2001, $3 \mathrm{~d}$ weighed dietary records ( $n$ 4993) from 849 children and adolescents (416 male, 433 female) aged $2-18$ years were collected and evaluated. Overall mean intake of added sugars was 12.4 (SD 5.3) (median 12.0) \% energy. Fat intake (\% energy) and intake of all analysed nutrients (as \% reference values for nutrient intakes) fell across quintiles $1-5$ of energy intake from added sugars $(P<0 \cdot 001)$. With the exception of 'Sugary foods' and 'Beverages' (significant increase, $P<0 \cdot 0001$ ) and 'Dairy' (NS), intake of all other food groups decreased with increasing intake of added sugars $(P<0 \cdot 0001)$. In conclusion, we found a slight, but statistically significant, nutrient-dilution effect of added sugars and a significant reduction in intake of important nutrient-bearing food groups. However, the DONALD study gives no clear indicator on grounds of micronutrient dilution for a quantitative limit on intake of added sugars.
\end{abstract}

Added sugars: Nutrient intake: Food intake: Children: Adolescents

The acceptable intake of sugars in a healthy diet has been widely discussed, especially for children. In recent dietary guidelines, a moderate consumption is recommended, without defining a quantitative limit (Food and Agriculture Organization/World Health Organization, 1998; Deutsche Gesellschaft für Ernährung, 2000; US Department of Agriculture, US Department of Health and Human Services, 2000). As a population goal, the Eurodiet project recommended sugary food consumption on no more than four occasions per $\mathrm{d}$, based on the development of caries (Eurodiet, 2000). Previous guidelines defined an upper limit of $10 \%$ energy (E) intake from sugars (World Health Organization, 1990). Dietary intake data from the last few decades have consistently shown intakes of sugars above this limit in the diet of children and adolescents in Germany (Linseisen et al. 1998), in other European countries (Gibson, 1997b; Lyhne \& Ovesen, 1999) and in the USA (Krebs-Smith, 2001).

Recommendations for a limited intake of sugars are often based on the hypothesis of 'nutrient dilution'. Isolated sugars added to food provide $\mathrm{E}$, but no essential nutrients. Therefore, it is often suspected that diets high in added sugars have a lower nutrient density for several vitamins and minerals. In fact, a significantly reduced nutrient density (Lyhne \& Ovesen, 1999) or nutrient intake (Rugg-Gunn et al. 1991; Lewis et al. 1992;
Gibson, 1997b; Linseisen et al. 1998; Bowman, 1999) with increasing intake of sugars was found in several studies in children and/or adolescents. However, the nutritional significance of nutrient dilution is controversial, since these changes were only small compared with overall nutrient intakes (Gibney et al. 1995; Forshee \& Storey, 2001).

The objectives of the present paper were to evaluate the effects of intake of added sugars on intakes of nutrients and food groups. We examined data from the ongoing Dortmund Nutritional and Anthropometric Longitudinally Designed (DONALD) study in a group of 2-18-year-old German children and adolescents between 1985 and 2001.

\section{Subjects and methods}

Subjects and study design

The DONALD study is a longitudinal study in which detailed data on diet, metabolism, growth and development have been collected from healthy subjects between infancy and adulthood. The study started in mid 1985, with children and adolescents of different ages participating in anthropometric studies at our Institute. Since then, annual cohorts of about forty to fifty healthy infants have been enrolled. Mothers are recruited in the city of Dortmund 
and surrounding communities via paediatric practices or personal contacts. Drop-out rates are small and vary by the age of the child, with the highest drop-out rate during puberty.

Participants $>2$ years old were examined annually. This medical examination was followed by a $3 \mathrm{~d}$ weighed dietary record. For this analysis, all $3 \mathrm{~d}$ weighed dietary records collected between July 1985 and August 2001 were considered, comprising 4993 dietary records from 849 children and adolescents (416 male, 433 female; aged 2-18 years) coming from 626 families. Between one ( $n$ 142) and sixteen records ( $n 4)$ per study participant were available (mean value 5.9). Mean age ranged from $6 \cdot 7$ (SD 4.1) to 9.6 (SD 4.7) years old per study year.

The DONALD study is an exclusively observational, non-intervening and non-invasive study and is approved by the International Scientific Committee of the Research Institute of Child Nutrition.

\section{Dietary survey}

Parents of the children, or the older subjects themselves, weighed and recorded all foods and fluids consumed and leftovers using electronic food scales $( \pm 1 \mathrm{~g})$ on three consecutive days. Recipes for home-prepared meals were recorded. At the end of the $3 \mathrm{~d}$ record period, our dietitians visited the family and checked the record for completeness and accuracy. Product information from wrappers, cartons, etc. were kept and evaluated. If further queries turned up during the coding, the dietitians contacted the participant by telephone. Semi-quantitative recording (e.g. number of spoons, scoops) was allowed if weighing was not possible. However, in $75 \%$ of the completed records, more than $90 \%$ of the food items were weighed (Kersting et al. $1998 b)$.

Record-keeping switched from the parents to the children or adolescents depending on age. Some children assisted their parents in recording from the age of 7 years. Of the 10-12-year-old children, $80 \%$ helped with the recording. In the adolescent groups, totally self-reliant records were kept by $20 \%$ of the male and $30 \%$ of the female subjects aged 13-14 years and by $70 \%$ of the male and $90 \%$ of the female subjects aged 15-18 years (Kersting et al. 1998b).

The first day of recording was chosen by participants. However, weekdays $(71.4 \%)$ and weekend days $(28.6 \%)$ were proportionally distributed in the sample.

To validate dietary recording, the reported $\mathrm{E}$ intake:predicted BMR ratio was used. BMR was calculated using the equations of Schofield (1985) including measured height and weight of the individuals. The mean $\mathrm{E}$ intake:BMR ratios of the sample were in the range of plausible dietary information (between 1.28 and 1.79 for children aged $1-5$ years, between 1.39 and $2 \cdot 24$ for boys aged $6-18$ years and between 1.30 and $2 \cdot 10$ for girls aged $6-18$ years) according to Torun et al. (1996).

$\mathrm{E}$ and nutrient intakes were calculated using our nutrient database LEBTAB, which is continuously updated by all new recorded food items. At present, LEBTAB contains about 4900 food items (60\% foods, composites and commercial products, $30 \%$ commercial infant food products and $10 \%$ special preparations). Nutrient contents of common foods were taken from standard nutrient tables (Holland et al. 1992; Voorlichtingsbureau, 1993; Souci et al. 2000). Nutrient contents of commercial food products were determined either by using the product labels or by simulating recipes from the ingredients listed, including nutrient contents of fortified foods.

\section{Definition of added sugars and food groups}

Added sugars were defined as all refined sugars (e.g. sucrose, maltose, lactose, glucose, dextrin) eaten separately at the table or used as ingredients in processed or prepared foods, as done for the recent US dietary guidelines (US Department of Agriculture, US Department of Health and Human Services, 2000) and by other authors (Lewis et al. 1992; Lyhne \& Ovesen, 1999; Forshee \& Storey, 2001). Although natural intrinsic sugars and added sugars are indistinguishable with regard to chemical analysis or physiological metabolism, this separation provides consumers with useful information, especially if they are trying to limit excessive use of energy-containing sweeteners (Johnson \& Frary, 2001). The definition of food groups is given in Table 1.

\section{Statistical analysis}

SAS ${ }^{\circledR}$ procedures (version 6.12; Statistical Analysis Systems, Cary, NC, USA) were used for data analysis (SAS Institute Inc., 1997). Intakes of nutrients and food groups were calculated as individual mean values of the three recorded days. A significance level of $P<0.05$ was used.

Nutrient intakes were calculated as individual percentage of recent Reference Values for Nutrient Intakes, jointly edited by the nutrition societies of the Germanspeaking countries (Deutsche Gesellschaft für Ernährung, 2000). Fat intake was given as \% E. Food group intakes were calculated as individual \% total food intake (TFI).

Table 1. Definition of food groups

\begin{tabular}{|c|c|}
\hline Food group & Including foods \\
\hline Dairy & $\begin{array}{l}\text { Milk, yoghurt, dairy products, } \\
\text { cheese }\end{array}$ \\
\hline Meat, fish and eggs & $\begin{array}{l}\text { Poultry, sausages, fish and } \\
\text { egg products }\end{array}$ \\
\hline Fats and oils & $\begin{array}{l}\text { Discrete fats and oils } \\
\text { from plant and animal } \\
\text { origin, mayonnaise }\end{array}$ \\
\hline Grain & $\begin{array}{l}\text { Bread, breakfast cereals, cereals, } \\
\text { flours, pasta, rice, potatoes, } \\
\text { potato products, e.g. french } \\
\text { fries }\end{array}$ \\
\hline Fruits and vegetables & $\begin{array}{l}\text { Fresh, canned and frozen } \\
\text { products, juices }\end{array}$ \\
\hline Beverages & $\begin{array}{l}\text { Tap water, mineral water, } \\
\text { coffee, tea, soft drinks, } \\
\text { fruit juice drinks, malt } \\
\text { beverage }\end{array}$ \\
\hline Sugary foods & $\begin{array}{l}\text { Table sugar, syrups, marzipan, } \\
\text { nougat, sweets, cakes, jam, } \\
\text { chocolate, ice cream }\end{array}$ \\
\hline Miscellaneous & Spices, convenience dishes \\
\hline
\end{tabular}


To examine associations between added sugars and intakes of nutrients or food groups, a mixed linear model was used, in which the mean values, the covariance structure and the effect of repeated measurements were measured (PROC MIXED) (Littell et al. 1996). An exponential structure of covariance was specified to consider correlation of repeated measurements dependent on the absolute time interval of repeated measurements within the same subject.

Age (respective age of the participant), time (year of recording) and sex effects were included in each model.

In detail, we tested the following model: intake of nutrients (\% reference value $(\mathrm{RV})$ or $\% \mathrm{E})$ or food group $(\% \mathrm{TFI})=$ intercept $+\beta 1$ (intake of added sugars, in fifth of $\% \mathrm{E}+\beta 2$ (time, years) $+\beta 3$ (age, years) $+\beta 4$ (gender).

The coefficients for independent variables ( $\beta 1$ to $\beta 4)$ represent their predicted change when the reported independent variable increased by one unit. For example, the coefficient for added sugars $(\beta 1)$ represents the predicted change in intakes of nutrients or food groups when the reported consumption of added sugars intake ascend to the next quintile. The coefficient for time $(\beta 2)$ or age ( $\beta 3)$ predicted the change in intake of nutrient or food group for a 1-year increase in study duration or age. The coefficient of the gender variable $(\beta 4)$ represents the predicted change of intake of nutrient or food group consumed by female compared with male subjects.

\section{Results}

Overall intake of added sugars was 12.4 (SD 5.3) (median 12.0) \% E. Quintile cut-points of added sugars intake were $7.9,10.8,13.3$ and $16.6 \%$ E respectively.

Table 2 shows associations between quintiles for intakes of added sugars and nutrients. Intakes of fat, vitamins and minerals were strongly inversely associated with intake of added sugars. As intake of added sugars rose, median fat intake decreased from $38 \% \mathrm{E}$ at the lowest quintile to $34 \% \mathrm{E}$ intake at the highest quintile, a decrease of $10 \%$ (Fig. 1). Median intakes of vitamin A, $\mathrm{C}$, thiamin, folate, $\mathrm{Ca}$ and $\mathrm{Fe}$ decreased by $22,3,3,15$, 14 and $6 \%$ respectively (Fig. 1).
Time and age trends were heterogeneous. Intakes of fat (\% E) and folate (\% RV) decreased during the study period, whereas intake of vitamin $\mathrm{C}$ increased. $\mathrm{Ca}$ intake $(\% \mathrm{RV})$ decreased with age, whereas intakes of thiamin, folate and $\mathrm{Fe}$ increased.

Nutrient intakes were lower in girls than in boys; however, the differences were not significant for fat $(\% \mathrm{E})$ and Vitamin C (\% RV).

The food groups 'Sugary foods' (55.8 (SD 22.1)\% total intake of added sugars) and 'Beverages' (20.3 (SD 19.3) \% total intake of added sugars) were the main contributors to intake of added sugars, followed by 'Dairy' (13.4 (SD 15.7) \% total intake of added sugars), 'Grain' (6.8 (SD 10.8) \% total intake of added sugars), 'Fruits and vegetables' (2.4 (SD 6.1)\% total intake of added sugars) and 'Fats and oils' and 'Meat, fish and eggs' (both $<1 \%$ total intake of added sugars).

There was no association between intake of added sugars and 'Dairy' intake (\% TFI) (Table 3). Intakes of 'Meat, fish and eggs', 'Fats and oils', 'Grain' and 'Fruits and vegetables' fell with increasing added sugars intake $(P<0 \cdot 0001)$. Intake of 'Beverages' and 'Sugary food' increased with increasing added sugars intake $(P<0.0001)$.

The greatest effect of intake of added sugars was found for 'Fruits and vegetables'. Here, a $10 \%$ TFI difference across quintiles was found (approximately 40\%). Median intake of 'Grain', 'Fats and oils' and 'Meat, fish and eggs' decreased by 17,15 and $4 \%$ respectively. Median intake of 'Sugary food' (\% TFI) at quintile 5 was more than doubled than in quintile $1(+162 \%)$ and median intake of beverages (\% TFI) increased by more than onethird (+43\%) (Fig. 2).

\section{Discussion}

Intake of added sugars in the diet of children and adolescents from the DONALD study $(10-13 \%$ E) was very similar to the values found in a representative study in Germany (12-14\% E as total sucrose in 4-18-year-olds; Linseisen et al. 1998) and Denmark (14\% E as added sugars in 4-14-year olds; Lyhne \& Ovesen, 1999). Intakes of sugars in the UK (non-milk extrinsic sugars in preschool children (\% E): boys 17.5, girls 18.2; Gibson, 1997b) and

Table 2. Overall intake and associations between intakes of added sugars nutrients in 2-18-year-old participants of the Dortmund Nutritional and Anthropometric Longitudinally Designed (DONALD) study 1985-2001*

\begin{tabular}{|c|c|c|c|c|c|c|c|c|c|}
\hline \multirow[b]{2}{*}{ Nutrient§ } & \multirow[b]{2}{*}{ Intercept } & \multicolumn{2}{|c|}{ Added sugars $†$} & \multicolumn{2}{|c|}{ Timeł } & \multicolumn{2}{|c|}{ Age } & \multicolumn{2}{|c|}{ Gender } \\
\hline & & $\beta 1$ & $P$ & $\beta 2$ & $P$ & $\beta 3$ & $P$ & $\beta 4$ & $P$ \\
\hline Fat $(\% \mathrm{E})$ & $42 \cdot 71$ & -1.00 & $<0.0001$ & -0.28 & $<0.0001$ & 0.05 & 0.0580 & -0.26 & 0.2561 \\
\hline Vitamin A (\% RV)§ & $105 \cdot 40$ & -3.65 & $<0.0001$ & -0.15 & 0.4937 & -0.04 & 0.8584 & $-4 \cdot 38$ & 0.0267 \\
\hline Vitamin C (\% RV) & 120.97 & -3.07 & $<0.0001$ & $1 \cdot 17$ & 0.0002 & 0.21 & 0.5190 & $-5 \cdot 34$ & 0.0928 \\
\hline Thiamin (\% RV) & 97.52 & -0.92 & 0.0378 & 0.10 & 0.5428 & 0.58 & 0.0011 & -5.57 & 0.0006 \\
\hline Folate (\% RV) & 52.68 & -1.33 & $<0.0001$ & -0.18 & 0.0394 & 0.23 & 0.0153 & $-3 \cdot 87$ & $<0.0001$ \\
\hline Calcium (\% RV) & $123 \cdot 17$ & $-1 \cdot 37$ & $<0.0001$ & 0.16 & 0.2625 & -1.47 & $<0.0001$ & $-12 \cdot 34$ & $<0.0001$ \\
\hline Iron (\% RV) & $105 \cdot 33$ & -0.93 & 0.0002 & -0.21 & 0.0520 & 0.89 & $<0.0001$ & $-15 \cdot 30$ & $<0.0001$ \\
\hline
\end{tabular}

${ }^{*}$ For details of subjects and procedures, see pp. 441-442.

$\mathrm{E}$, energy; RV, reference value.

$\dagger$ Fifths of $\% E$ intake from added sugars.

$\ddagger$ Years.

§ Reference value (RV), Deutsche Gesellschaft für Ernährung (2000). 

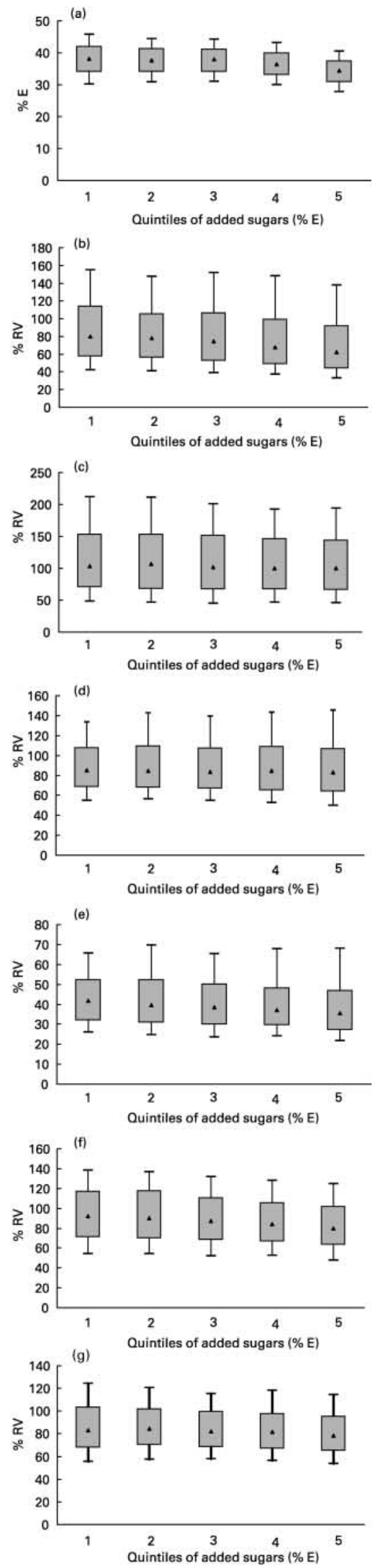

the USA (added sugars (\% E): 2-5-year-olds 16, 12-19year-olds 20; Krebs-Smith, 2001) were somewhat higher, but definitions of sugars are not always comparable between studies. All surveys have in common that intake of sugars was above the previous limit of $10 \% \mathrm{E}$.

As found by others in cross-sectional surveys (Gibney et al. 1995; Hill \& Prentice, 1995; Gibson, 1997b; Farris et al. 1998; Bowman, 1999), the effect of intake of added sugars on fat intake was negative ('sugar:fat seesaw' phenomenon), indicating that intake of added sugars at least partially replaced fat intake.

Our present results clearly showed a general trend of declining nutrient intakes as \% RV (Deutsche Gesellschaft für Ernährung, 2000) with increasing intake of added sugars. However, the nutritional significance of this effect must be considered. As also stated by Forshee \& Storey (2001), Gibson (1997a), Lewis et al. (1992) and Lyhne \& Ovesen (1999), intakes of most nutrients were adequate regardless of the level of intake of added sugars. In the diet of children and adolescents in the DONALD study, intakes of folate were well below RV. However, comparing folate intakes at different levels of intake of added sugars (Fig. 1), this borderline intake was found even at the lowest as at the highest quintile.

In the German National Food Consumption Survey (1985-9) 'Confectionery and ice cream', 'Dairy' and 'Non-alcoholic beverages' were the main food groups contributing to sucrose intake in children and adolescents (Linseisen et al. 1998). In the US diet, carbonated soft drinks contributed $33 \%$ to the total intake of added sugars, reflecting the dominance of this food group on intake of added sugars in the US diet. Other considerable sources for added sugars were 'Fruit drinks' $(10 \% \mathrm{E})$, 'Candy' (\% E) 'Cakes' (5 \% E) and 'Ready-to-eat-cereals' $(4 \% \mathrm{E})$. In contrast to the results of the DONALD study, the importance of dairy products as a source of added sugars was only small (<4\% E) (Krebs-Smith, 2001).

Associations between intakes of food groups and added sugars found in the DONALD study are consistent with previous studies. In the Bogalusa Heart study, intakes of 'Beverages' and 'Candy' increased and those of 'Mixed meats', 'Beef' and 'Poultry' decreased with increasing intake of added sugars in 10-year-old children (Farris et al. 1998). Only a small negative association, without practical importance, between added sugars and 'Dairy' was found by Forshee \& Storey (2001), analysing data from the 1994-6 US Continuing Survey of Food Intakes by Individuals. In this evaluation, a weak negative association between added sugars and 'Fruits and vegetables' was also found. Although this food group is the most

Fig. 1. Distribution of nutrients by quintiles of energy intake from added sugars in 2-18-year-old participants in the Dortmund Nutritional and Anthropometric Longitudinally Designed (DONALD) study: (a), fat (\% energy (E)); (b), vitamin A (\% reference value (RV, Deutsche Gesellschaft für Ernährung (2000)); (c), vitamin C (\% RV); (d), thiamin (\% RV); (e), folate (\% RV); (f), calcium (\% RV); (g) iron (\% RV). For details of subjects and procedures, see pp. 441-442. Values are medians $(\boldsymbol{\Delta})$, with the 25th and 75 th centiles shown by the horizontal limits of the box and 10th and 90 th centiles by vertical lines. 

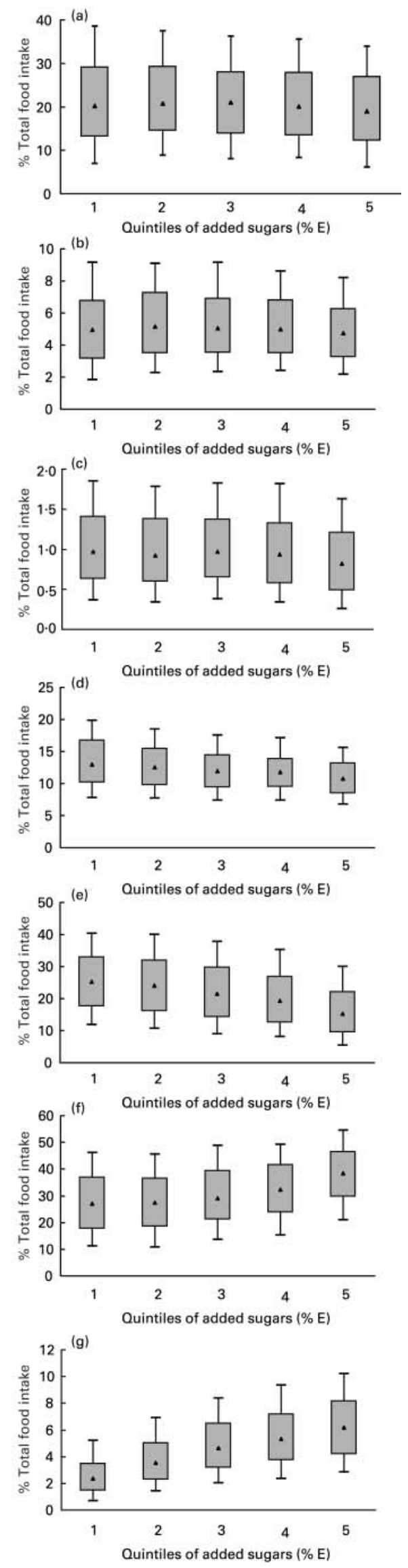

important contributor to vitamin $\mathrm{C}$ intake, intake of this vitamin was positively associated with intake of added sugars, whereas in the DONALD Study, a negative association was found. Obviously, the negative effect of added sugars intake on the intake of fruit and vegetables exceeded the positive effect of fortification of sweetened food products. As we have shown in a previous evaluation, nutrient fortification masks nutrient dilution by added sugars (Alexy et al. 2002b). In a market survey in Germany, our Institute found most fortified products among the food groups 'Beverages', 'Sweets' and 'Cereals' (Kersting et al. 1995), which are also important contributors to intake of added sugars. Thus, $56 \%$ of all fortified food products in Germany contained additional added sugars (Kersting et al. 1995). As described by Sichert-Hellert et al. (2000) on the basis of the DONALD study between 1985 and 1996, intake of added sugars from fortified food (\% TFI) increased disproportionately to $\mathrm{E}$ intake (\% TFI). Obviously, fortification is used as a marketing instrument by the food industry to validate nutritionally unfavourable high-sugar products. However, fruits and vegetables confer a benefit beyond nutrients, since they contain many phytochemicals that are believed to be beneficial on health, although phytochemicals are not nutrients in the true sense of the word and not added back in fortification. This means that added sugars may dilute not only nutrients, but also non-nutrient food components.

Some limitations of the present study should be considered in interpreting the findings. First, the DONALD study sample is not representative, upper social class families are over-represented (Kersting et al. $1998 b)$. However, several evaluations showed no or only minor differences in dietary habits in our sample compared with the previous German National Food Consumption Survey (Alexy et al. 1998, 1999; Kersting et al. $1998 a, b)$. Time trends of dietary habits are also comparable, for example, with findings of the MONICA study in German adults (Alexy et al. 2002a).

Second, potential under-reporters were not excluded from analysis. In a longitudinally designed study such as the DONALD study, direct estimation of under-reporting, for example by doubly-labelled water, is usually not feasible. By an indirect identification of under-reporting, e.g. by cut-offs for the E intake:BMR ratio, as suggested by Goldberg (1991), a distinction between real underreporters and those with an habitual low-E intake is not possible. In addition, after excluding implausible records $(5 \%)$ from 4-18-year-old females ( $\mathrm{E}$ intake: BMR ratio below cut-offs suggested by Sichert-Hellert et al. (1998) for children and adolescents), results were very similar to those of the total sample (results not shown).

Fig. 2. Distribution (\% total food intake) of food groups by quintiles of energy intake from added sugars in 2-18-year-old participants in the Dortmund Nutritional and Anthropometric Longitudinally Designed (DONALD) study: (a), dairy; (b), meat, fish and eggs; (c), fats and oils; (d), grain; (e), fruits and vegetables; (f), beverages; (g), sugary foods. For details of subjects and procedures, see pp. 441-442 and for details of food groups, see Table 1. Values are medians $(\boldsymbol{\Delta})$, with the 25th and 75th centiles shown by the horizontal limits of the box and 10th and 90th centiles by vertical lines. 
Table 3. Overall intake and associations between intakes of added sugars and food groups in 2-18-year-old participants of the Dortmund Nutritional and Anthropometric Longitudinally Designed (DONALD) study 1985-2001*

\begin{tabular}{|c|c|c|c|c|c|c|c|c|c|}
\hline \multirow[b]{2}{*}{ Nutrient ( $\%$ total food intake) } & \multirow[b]{2}{*}{ Intercept } & \multicolumn{2}{|c|}{ Added sugarst } & \multicolumn{2}{|c|}{ Time‡ } & \multicolumn{2}{|c|}{ Age $\neq$} & \multicolumn{2}{|c|}{ Gender } \\
\hline & & $\beta 1$ & $P$ & $\beta 2$ & $P$ & $\beta 3$ & $P$ & $\beta 4$ & $P$ \\
\hline Meat, fish and eggs & 7.05 & -0.18 & $<0.0001$ & -0.12 & $<0.0001$ & 0.06 & $<0.0001$ & -0.27 & 0.0292 \\
\hline Fats and oils & $1 \cdot 37$ & -0.04 & $<0.0001$ & -0.04 & $<0.0001$ & 0.02 & $<0.0001$ & 0.00 & 0.9430 \\
\hline Grain & $13 \cdot 10$ & -0.46 & $<0.0001$ & -0.04 & 0.0207 & 0.19 & $<0.0001$ & -0.38 & 0.0609 \\
\hline Fruits and vegetables & $28 \cdot 73$ & $-2 \cdot 25$ & $<0.0001$ & 0.02 & 0.6272 & -0.40 & $<0.0001$ & 1.88 & 0.0002 \\
\hline Sugary foods & 2.47 & 0.83 & $<0.0001$ & -0.05 & $<0.0001$ & 0.03 & 0.0095 & 0.33 & 0.0008 \\
\hline
\end{tabular}

${ }^{*}$ For details of subjects and procedures, see pp. 441-442.

$\dagger$ Fifths of \% energy intake from added sugars.

$\ddagger$ Years.

In summary, analysis of dietary data from the DONALD study gives no clear indicator of micronutrient dilution for a quantitative limit of intake of added sugars. Obviously, an adequate nutrient intake is still possible within a wide range of added sugars intake (Gibson, 1997a; Ruxton et al. 1999). Others authors found no compromised nutrient intakes for non-milk extrinsic sugars intakes up to about $16 \% \mathrm{E}$ intake in children (Gibson, 1997b) and non-milk extrinsic sugars up to $20 \% \mathrm{E}$ intake in adults (Gibson, $1997 a$ ), values well above the mean intake of added sugars in children and adolescents of the DONALD study. In addition, Ruxton et al. (1999) concluded, after reviewing published literature, that consuming average amounts of sugars $(14-20 \%$ E) had no detrimental effects on micronutrient intakes, even in children. However, a negative association between added sugars and intakes of all vitamins and minerals was found, so that added sugars intake should not be fully liberal.

\section{Acknowledgements}

This work was supported by the Ministry of Education, Science and Research North Rhine-Westphalia, Germany, and the German Federal Ministry of Consumer Protection, Food and Agriculture. Furthermore, we are very grateful to Christa Chahda and Ruth Schäfer for collecting and coding the dietary records in the DONALD study and to Diane Pavlitzek for proofreading.

\section{References}

Alexy U, Kersting M, Sichert-Hellert W, Manz F \& Schöch G (1998) Energy intake and growth of 3 to 36-month-old German infants and children. Ann Nutr Metab 42, 68-74.

Alexy U, Kersting M, Sichert-Hellert W, Manz F \& Schöch G (1999) Macronutrient intake of 3- to 36-month-old German infants and children: results of the DONALD Study. Ann Nutr Metab 43, 14-22.

Alexy U, Sichert-Hellert W \& Kersting M (2002a) Fifteen-year time trends in energy and macronutrient intake in German children and adolescents: results of the DONALD study. $\mathrm{Br} \mathrm{J}$ Nutr 87, 595-604.

Alexy U, Sichert-Hellert W \& Kersting M (2002b) Fortification masks nutrient dilution due to added sugars in the diet of children and adolescents. J Nutr 132, 2785-2791.
Bowman SA (1999) Diets of individuals based on energy intakes from added sugars. Fam Econ Nutr Rev 12, 31-38.

Deutsche Gesellschaft für Ernährung (2000) Referenzwerte für die Nährstoffzufuhr (Reference values for nutrient intake). Frankfurt am Main: Umschau/Braus.

Eurodiet (2000) Core report. http://eurodiet.med.uoc.gr/

Farris RP, Nicklas TA, Myers L \& Berenson GS (1998) Nutrient intake and food group consumption of 10-year-olds by sugar intake level: the Bogalusa Heart Study. J Am Coll Nutr 17, 579-585.

Food and Agriculture Organization/World Health Organization (1998) Carbohydrates in Human Nutrition. Report of a Joint FAO/WHO Expert Consultation. FAO Food and Nutrition Paper no. 66. Geneva: WHO.

Forshee RA \& Storey ML (2001) The role of added sugars in the diet quality of children and adolescents. $J$ Am Coll Nutr 20 , $32-43$.

Gibney M, Sigman-Grant M, Stanton JL Jr \& Keast DR (1995) Consumption of sugars. Am J Clin Nutr 62, Suppl. 1, 178S-193S.

Gibson SA (1997a) Do diets high in sugars compromise micronutrient intakes? J Hum Nutr Diet 10, 125-133.

Gibson SA (1997b) Non-milk extrinsic sugars in the diets of pre-school children: association with intakes of micronutrients, energy, fat and NSP. Br J Nutr 78, 367-378.

Goldberg GR, Black AE, Jebb SA, et al. (1991) Critical evaluation of energy intake data using fundamental principles of energy physiology: 1 . Derivation of cut-off limits to identify under-recording. Eur J Clin Nutr 45, 569-581.

Hill JO \& Prentice AM (1995) Sugar and body weight regulation. Am J Clin Nutr 62, Suppl. 1, 264S-273S.

Holland B, Welch AA, Unwin ID, Buss DH, Paul AA \& Southgate DAT (1992) McCance and Widdowson's the Composition of Foods, 5th and Extended Edition. Cambridge: Royal Society Chemistry Ministry of Agriculture, Fisheries and Food.

Johnson RK \& Frary C (2001) Choose beverages and foods to moderate your intake of sugars: the 2000 dietary guidelines for Americans - what's all the fuss about? J Nutr 131, 2766S-2771S.

Kersting M, Hansen C \& Schöch G (1995) Übersicht der derzeitigen Nährstoffanreicherung von Lebensmitteln in Deutschland (A survey of the Present-day Supply of Fortified Food Products in Germany) $Z$ Ernährungswiss 34, 253-260.

Kersting M, Sichert-Hellert W, Alexy U, Manz F \& Schöch G (1998a) Macronutrient intake of 1 to 18 year old German children and adolescents. $Z$ Ernahrungswiss 37, 252-259.

Kersting M, Sichert-Hellert W, Lausen B, Alexy U, Manz F \& Schöch G (1998b) Energy intake of 1 to 18 year old German children and adolescents. Z Ernahrungswiss 37, 47-55. 
Krebs-Smith SM (2001) Choose beverages and foods to moderate your intake of sugars: measurement requires quantification. J Nutr 131, 527S-535S.

Lewis CJ, Park YK, Dexter PB \& Yetley EA (1992) Nutrient intakes and body weights of persons consuming high and moderate levels of added sugars. J Am Diet Assoc 92, 708-713.

Linseisen J, Gedrich K, Karg G \& Wolfram G (1998) Sucrose intake in Germany. Z Ernahrungswiss 37, 303-314.

Littell RC, Milliken GA, Stroup WW \& Wolfinger RD (1996) SAS® System for Mixed Models. Cary, NC: SAS Institute Inc.

Lyhne N \& Ovesen L (1999) Added sugars and nutrient density in the diet of Danish children. Scand J Nutr 43, 4-7.

Rugg-Gunn AJ, Hackett AF, Jenkins GN \& Appleton DR (1991) Empty calories? Nutrient intake in relation to sugar intake in English adolescents. J Hum Nutr Diet 4, 101-111.

Ruxton CH, Garceau FJ \& Cottrell RC (1999) Guidelines for sugar consumption in Europe: is a quantitative approach justified? Eur J Clin Nutr 53, 503-513.

SAS Institute Inc. (1997) SAS/STAT ${ }^{\circledR}$ Software: Changes and Enhancements through Release 6.12. Cary, NC: SAS Institute Inc.

Schofield WN (1985) Predicting basal metabolic rate, new standards and review of previous work. Hum Nutr Clin Nutr 39, Suppl. 1, 5-41.
Sichert-Hellert W, Kersting M, Alexy U \& Manz F (2000) Ten-year trends in vitamin and mineral intake from fortified food in German children and adolescents. Eur J Clin Nutr $\mathbf{5 4}, 81-86$.

Sichert-Hellert W, Kersting M \& Schöch G (1998) Underreporting of energy intake in 1 to 18 year old German children and adolescents. Z Ernahrungswiss 37, 242-251.

Souci SW, Fachmann W \& Kraut H (2000) Food Composition and Nutrition Tables, 6 ed. Stuttgart: Medpharm Scientific Publisher.

Torun B, Davies PS, Livingstone MB, Paolisso M, Sackett R \& Spurr GB (1996) Energy requirements and dietary energy recommendations for children and adolescents 1 to 18 years old. Eur J Clin Nutr 50, Suppl. 1, S37-S80.

US Department of Agriculture, US Department of Health and Human Services (2000) Nutrition and Your Health: Dietary Guidelines for Americans, 5th ed., Home and Garden Bulletin no. 232. Washington, DC: US Government Printing Office.

Voorlichtingsbureau voor de Voeding (ed) (1993) Nevo Tabel. Den Haag: Nederlands voedingsstoffenbestand.

World Health Organization (1990) Diet, Nutrition and Prevention of Chronic Diseases. Technical Report Series no. 797. Geneva: WHO. 